\title{
Distribution of Polycyclic Aromatic Hydrocarbons between the Particulate and the Gas Phase of Mainstream Cigarette Smoke in Relation to Cigarette Technological Characteristics*
}

\author{
by \\ M. Kalaitzoglou and C. Samara \\ Environmental Pollution Control Laboratory, Department of Chemistry, Aristotle University, 54124 Thessaloniki, Greece
}

\section{SUMMARY}

Particulate- and gas-phase polycyclic aromatic hydrocarbons (PAHs) were determined in the mainstream smoke (MSS) of 59 manufactured cigarette brands (commercially available brands of unknown tobacco and blend type) with variable 'tar' yields and physical/technological characteristics. Depending on the existence/absence of filter, the 'tar' yield indicated on the packet, and the cigarette length and diameter, the examined cigarette brands were classified into 15 groups: non filter (NF), high $(\mathrm{H})$, medium $(\mathrm{M})$, light (L), super light (SL), ultra light (UL), one-tar yields (O), $100 \mathrm{~mm}$ long cigarettes (H-100, L-100, SL-100, UL100, O-100), and slim cigarettes (SL-SLIM, UL-SLIM, OSLIM). Cigarettes were smoked in a reference smoking machine equipped with glass fibre filters for collection of PAHs bound to total particulate matter (TPM), and polyurethane foam plugs (PUF) for collection of gas-phase PAHs. The relationships of gas- and particulate-phase concentrations of PAHs (ng/cig) with the contents of typical MSS components, such as TPM, 'tar', nicotine and carbon monoxide were investigated. In addition, the phase partitioning of PAHs in MSS was evaluated in relation to the technological characteristics of cigarettes. [Beitr. Tabakforsch. Int. 21 (2005) 331-344]

\section{ZUSAMMENFASSUNG}

Das Vorkommen polyzyklischer aromatischer Kohlenwasserstoffe (PAH) in der Partikel- und der Gasphase des Hauptstromrauchs (HSR) von 59 verschiedenen, industriell hergestellten Zigaretten (im Handel erhältliche Marken unbekannter Tabaksorte und Mischung) mit unterschiedlichem Kondensatgehalt und physikalischen/technologischen Eigenschaften wurde bestimmt. Je nach Vorhandensein bzw. Nichtvorhandensein eines Filters, dem auf der Verpackung angegebenen Kondensatgehalt sowie der Länge und des Durchmessers der Zigaretten wurden die untersuchten Zigarettenmarken in 15 Gruppen unterteilt: ohne Filter (NF), hoher $(\mathrm{H})$, mittlerer $(\mathrm{M})$, niedriger $(\mathrm{L})$ Kondensatgehalt, super light (SL), ultra light (UL), 1 mg Kondensatklasse (O), 100 mm Zigaretten (H-100, L-100, SL-100, UL-100, O-100) sowie ,schlanke" Zigaretten (SL-SLIM, UL-SLIM, OSLIM). Die Zigaretten wurden mit einer Referenz-Rauchmaschine abgeraucht, die zum Sammeln der partikelgebundenen PAHs mit einem Glasfaserfilter und zum Auffangen der Gasphasen-PAHs mit einem Polyurethan-Schaumstoffkartusche (PUF) ausgestattet war. Der Zusammenhang zwischen den PAH-Konzentrationen (ng/Zigarette) in der Gasund Partikelphase und dem Vorkommen typischer HSRKomponenten wie Gesamtpartikelmasse (TPM), Kondensat, Nikotin und Kohlenmonoxid wurde untersucht. Außerdem wurde die Phasenverteilung der PAHs im Hauptstromrauch in Abhängigkeit von den technologischen Eigenschaften der Zigaretten bestimmt. [Beitr. Tabakforsch. Int. 21 (2005) 331-344]

\section{RESUME}

La présence d'hydrocarbures aromatiques polycycliques (PAH) dans les phases particulaire et gazeuse de la fumée du courant principal (CP) de 59 marques de cigarettes fa-

* Received: $22^{\text {nd }}$ September 2004 - accepted: $5^{\text {th }}$ April 2005 
briquées industriellement (vendues dans le commerce, fabriquées de tabacs et mélanges inconnus) ayant différents rendements en goudron et caractéristiques physiques/technologiques, a été examinée. Selon l'existence/absence d'un filtre, la teneur en goudron indiquée sur le paquet ainsi que la longueur et le diamètre de la cigarette, les cigarettes étudiées ont été classées en 15 groupes: sans filtre $(\mathrm{NF})$, plein arôme $(\mathrm{H})$, moyennes $(\mathrm{M})$, légères (L), super-légères (SL) ultra-légères (UL), $1 \mathrm{mg}$ de goudron (O), cigarettes de $100 \mathrm{~mm}$ (H-100, L-100, SL-100, UL-100, O-100) et cigarettes minces (SL-SLIM, ULSLIM, O-SLIM). Les cigarettes ont été fumées sur une machine à fumer de référence, équipée de filtres en fibres de verre pour la collecte des PAH liés à la matière particulaire totale (TPM), et de tampons de polyuréthane (PUF) pour la collecte des PAH dans la phase gazeuse. Les relations entre la teneur en PAH (ng/cigarette) dans les phases particulaire et gazeuse et la teneur en composants typiques du CP, comme le TPM, le goudron, la nicotine et le monoxyde de carbone, ont été examinées. De plus, le partage des PAH entre les deux phases du CP a été évalué en fonction des caractéristiques technologiques des cigarettes. [Beitr. Tabakforsch. Int. 331-344]

\section{INTRODUCTION}

Cigarette mainstream smoke (MSS) is a complex aerosol consisting of a vapour and a particulate phase. It has been reported that approximately $8 \%$ of the total composition of MSS exists as particulate matter, with the remainder being composed of various gases and organic vapours. Some components (e.g. carbon monoxide and carbon dioxide) are found primarily in the vapour phase, while others, such as phytosterols, predominate in the particulate phase. Compounds of medium volatility, such as phenol and the cresols, are partitioned between the vapour and particulate phases. In tobacco smoke, the term "semivolatiles" has been used to describe the volatile fraction of the particulate phase of smoke. This fraction includes acidic, basic and neutral compounds important for the flavor and, in some cases, for the physiological effects of smoke (1).

Cigarette design has been largely evolved over the last decades with the incorporation of new tobacco processes, papers, filters, and several ingredients (flavorants, casing materials, humectants), which either alone or in combination have the potential to modify the quantity and/or the quality of the smoke yielded from the cigarette $(2,3)$. The incorporation of these new technologies and materials has resulted in the development of a diverse market of commercial cigarettes encompassing a wide range of 'tar' yields. Collectively, these technologies interact within the complex system of the burning cigarette and, ultimately, influence the mainstream smoke formed during the smoking process (4).

Polycyclic aromatic hydrocarbons (PAHs) are formed during the incomplete combustion of organic matter under conditions of insufficient oxygen amounts, and their presence in both mainstream and sidestream tobacco smoke has been well documented (1,5-7). PAH formation mechanisms under tobacco smoking involve degradation of complex molecules and formation of simpler molecules or free radicals followed by recombination to form PAHs (8), or aromatisation of complex molecules, such as phytosterols, to form the many structures of PAHs. The major precursors of PAHs are reportedly solanesol, phytosterols, terpenes, amino acids, nicotine, lipids, cellulose and several other tobacco components $(9,10)$.

Many PAHs have been proven to be mutagens and/or carcinogens. PAHs like benzo $[a]$ pyrene, benz $[a]$ anthracene, and dibenz $[a, h]$ anthracene, which have been classified as probably carcinogenic to humans, and others like benzo[b]fluoranthene, benzo[ $k]$ fluoranthene, benzo[j]fluoranthene, dibenzo[a,e]pyrene, dibenzo[a,h]pyrene, dibenzo $[a, i]$ pyrene, dibenzo $[a, l]$ pyrene, indeno[ $[1,2,3-c d]$ pyrene, and 5-methylchrysene, classified as possible carcinogens, have been reported in cigarette MSS $(11,12)$. Nevertheless, many of the PAHs usually present in tobacco smoke have been found to be not only tumorigenic but also antitumorigenic to many of the most potent tumorigenic PAHs when administered simultaneously by several routes (skin painting, subcutaneous injection, etc.). Such antitumoric action has been reported for phenanthrene, fluoranthene, pyrene and benzo[e]pyrene vs. 7,12 dimethylbenz $[a]$ anthracene $(41,42)$.

PAHs span a broad spectrum of vapour pressures (e.g., from $1.1 \times 10^{-2} \mathrm{kPa}$ for naphthalene to $2 \times 10^{-13} \mathrm{kPa}$ for coronene at $25{ }^{\circ} \mathrm{C}$ ), hence those with vapour pressures above approximately $10^{-8} \mathrm{kPa}$ will be present in the ambient air substantially distributed between the gas and particulate phases of the atmosphere (13). Earlier studies on PAHs in MSS $(5,6)$ were mainly referred to cigarette smoke condensate, which includes primarily the particulate phase and secondarily semi-volatile components from the vapour phase that can dissolve or disperse into particulate components of MSS (14). More recent studies are focused almost exclusively on PAHs bound to the total particulate matter of MSS, the so-called TPM (15-18). Information concerning the occurrence of PAHs in the gas phase of MSS is very limited. GRIMMER et al. (19) identified 12 PAHs in the gas-phase MSS of a cigarette of unknown 'tar' yield collected on silanized polystyrene beads (Parapak PS), whereas in (18) no PAHs were detected in the gas-phase MSS of 10 Kentucky reference cigarettes (1R4F) collected in ice-cooled $n$-hexane liquid traps.

The major objectives of the present study were to examine the occurrence of the 16 US Environmental Protection Agency (EPA) PAHs in the gas- and particulate-phase MSS for a wide range of cigarette brands, and to investigate their phase distribution in relation to design characteristics, such as existence/absence of filter, 'tar' yield, cigarette length/diameter, ventilation rate and pressure drop. The potential associations of particulate- and gas-phase PAHs with cigarette design characteristics and other MSS components (e.g. TPM, 'tar', nicotine and CO) were examined in an attempt to identify the major influential factors.

\section{EXPERIMENTAL}

\section{Cigarette sampling and preparation}

A total of 59 brands of manufactured cigarettes (commercially available brands retailed in the Greek market over the period August-September 2001) were chosen for inclu- 
Table 1. The time program of the HPLC-fluorescence detector

\begin{tabular}{lcccc}
\hline $\begin{array}{l}\text { Time } \\
(\mathrm{min})\end{array}$ & $\begin{array}{c}\text { Excitation } \\
\text { wavelength }(\mathrm{nm})\end{array}$ & $\begin{array}{c}\text { Emission } \\
\text { wavelength }(\mathrm{nm})\end{array}$ & PAHs detected \\
\hline 6.0 & 275 & 350 & $\mathrm{~Np}$ \\
9.0 & 280 & 350 & $\mathrm{Ace}, \mathrm{F}$ \\
11.2 & 246 & 370 & $\mathrm{Ph}, \mathrm{An}$ \\
14.4 & 280 & 450 & $\mathrm{Fl}$ \\
15.0 & 270 & 390 & $\mathrm{Py}$ \\
20.0 & 260 & 420 & $\mathrm{~B}[\alpha] \mathrm{A}, \mathrm{Chry}$ \\
24.4 & 284 & 430 & $\mathrm{~B}[e] \mathrm{Py}, \mathrm{B}[b] \mathrm{FI}$ \\
28.8 & 290 & 430 & $\mathrm{~B}[k] \mathrm{Fl}, \mathrm{B}[\alpha] \mathrm{Py}$ \\
33.5 & 290 & 410 & $\mathrm{~dB}[\alpha, h] \mathrm{An}, \mathrm{B}[g h] \mathrm{Pe}$ \\
36.5 & 250 & 500 & $\mathrm{I}[1,2,3-c d] \mathrm{Py}$ \\
\hline
\end{tabular}

sion in the present survey. These brands were selected to include a wide range of 'tar' yields and variable physical cigarette characteristics (existence/absence of filter, cigarette length and diameter, ventilation rate, pressure drop, etc.). Preceding smoking, cigarettes were conditioned at constant relative humidity $(60 \pm 2 \%)$ and temperature $\left(22 \pm 1^{\circ} \mathrm{C}\right)$ for at least $48 \mathrm{~h}$ but less than 10 days (20). At least three determinations of each type of analysis were made in each brand.

\section{Cigarette smoking: Sampling of particulate- and vapour-phase MSS}

Twenty cigarettes from each brand were smoked according to International Standard (ISO) 3308 (21) in a Borgwaldt RM 20 CS smoking machine. The particulate phase of MSS was collected onto a $92 \mathrm{~mm}$ Cambridge filter pad to determine TPM and 'tar' according to ISO 4387 (22). The vapour phase of MSS was channeled through a polyurethane foam cartridge (PUF), which collected the vapourphase PAHs, into a polythene bag connected to a nondispersive infrared $\mathrm{CO}$ analyzer (Borgwaldt C24) for determination of carbon monoxide according to ISO 8454 (23). The determination of nicotine and water on Cambridge filter pads was performed by gas chromatography (GC) according to ISO 10315 (24) and 10362 (25) Standard Methods, respectively. Nicotine-free dry particulate matter (NFDPM, also known as 'tar') was calculated on a per-cigarette basis from the difference: TPM - (nicotine + water).

Filter pads were thermally treated (at $450{ }^{\circ} \mathrm{C}$ for $6 \mathrm{~h}$ ) before use to remove organic contaminants. PUF sorbent cartridges were pre-cleaned by sequential Soxhlet extraction with first acetonitrile and then $n$-hexane. After vacuum drying, the clean sorbent cartridges were stored in screw-capped glass jars wrapped in solvent-rinsed aluminum foil (or otherwise protected from light) before careful installation on the traps. All solvents used in experimental work were pesticide analytical grade.

\section{Determination of PAHs in MSS}

Standard methods for the quantitative determination of PAHs in tobacco smoke have not been established yet. Analysis of PAHs in TPM has been achieved by two major instrumental methods: high pressure liquid chromatography with fluorimetric detection (HPLC-FD) (15,26-28) and gas chromatography-mass spectrometry (GC-MS) selective ion monitoring (SIM) mode analysis (16-18). Gas chromatography-flame ionization detection (GC-FID) and GC-MS have been employed for PAH analysis in gas phase of MSS $(18,19)$. In the present study, PAHs in TPM were determined by reversed-phase HPLC with programmable fluorescence detection, while PAHs in the vapour phase of MSS were analysed by using the GC-MS SIM mode procedure.

Briefly, after completion of smoking and weighing of the filter holders, the filter pad was removed from its holder and transferred into a $150-\mathrm{mL}$ flask. The inside surfaces of the holder were wiped with further portions of the filter material that were also put in the flask. Each filter pad was thrice extracted with $40 \mathrm{~mL}$ cyclohexane each time under shaking at a medium speed for $30 \mathrm{~min}$. The extracts were combined and after the addition of $1 \mathrm{~mL}$ isooctane (keeper solvent) were rotary evaporated to $\sim 2 \mathrm{~mL}$. The condensate was loaded on a chromatographic column filled with $7 \mathrm{~g}$ neutral silica gel (Kieselgel 40, 70-230 mesh), cleaned by 24-h Soxhlet extraction with dichloromethane and activated for $24 \mathrm{~h}$ at $160{ }^{\circ} \mathrm{C}$ in order to separate the fraction of aliphatic hydrocarbons (AHs) and remove potential interferences, prior the analysis. The $\mathrm{AH}$ fraction was first eluted from the column by gravity with $25 \mathrm{~mL}$ of $n$-hexane, while the PAH fraction was subsequently eluted by 50 $\mathrm{mL}$ of $n$-hexane:DMC (40:60, v/v) mixture. The PAH factions were concentrated, cleaned up through 500-mg aminopropyl-SPE columns, solvent changed from hexane to acetonitrile and analysed by HPLC-FD.

The HPLC analyses were performed on a Hewlett Packard 1100 series system consisting of a vacuum degasser, a quaternary pump, a 5-mL injection loop, and a diode array detector (DAD). A fluorescence detector (HP1046A) is connected in series with the DAD to the output of a Vydac-PAH column $(250 \times 4.6 \mathrm{~mm}$, polymeric bonded silica) preceded by a guard column (Phenomenex Envirosep-PP, $30 \times$ $3.20 \mathrm{~mm}$ ). The mobile phase (flow rate $0.5 \mathrm{~mL} / \mathrm{min}$ ) was a $\mathrm{CH}_{3} \mathrm{CN}-\mathrm{H}_{2} \mathrm{O}$ gradient changing from $58 \%$ to $100 \% \mathrm{CH}_{3} \mathrm{CN}$ over 0-35 min and remaining at $100 \% \mathrm{CH}_{3} \mathrm{CN}$ for $10 \mathrm{~min}$. All analyses were carried out at room temperature. Ten pairs of excitation/emission wavelengths were used for PAH detection (Table 1). The system was calibrated with the NIST 1647b Standard PAH Mixture containing 16 PAHs, 15 species specified by the US EPA as priority pollutants: naphthalene $(\mathrm{Np})$, acenapthene (Ace), fluorene $(\mathrm{F})$, phenanthrene $(\mathrm{Ph})$, anthracene $(\mathrm{An})$, fluoranthene $(\mathrm{Fl})$, pyrene $(\mathrm{Py})$, benzo $[a]$ anthracene $(\mathrm{B}[a] \mathrm{An})$, chrysene (Chry), benzo $[e]$ pyrene $(\mathrm{B}[e] \mathrm{Py})$, benzo $[b]$ fluoranthene $(\mathrm{B}[b] \mathrm{Fl})$, benzo $[k]$ fluoranthene $(\mathrm{B}[k] \mathrm{Fl})$, benzo $[a]$ pyrene $(\mathrm{B}[a] \mathrm{Py})$, dibenz $[a, h]$ anthracene $(\mathrm{dB}[\alpha, h] \mathrm{An})$, benzo[ghi]perylene $(\mathrm{B}[g h i] \mathrm{Pe})$, indeno[1,2,3-cd]pyrene (IPy), plus benzo[e]pyrene (B[e]Py) which is frequently used as a reference PAH compound. Acenaphthylene, although contained in the standard was not determined because it is only weakly fluorescent.

Vapour-phase PAHs were recovered from PUFs using accelerated solvent extraction with a mixture of acetone:hexane (30:70, v/v) according to procedures previously optimized $(29,30)$. Internal standards (naphthalene$d_{8}$, acenaphthene- $d_{10}$, phenanthrene- $d_{10}$, chrysene- $d_{12}$, perylene- $\mathrm{d}_{12}$ ) and $1 \mathrm{~mL}$ isooctane (keeper solvent) were added. The extracts were rotary evaporated to $\sim 5 \mathrm{~mL}$ and 


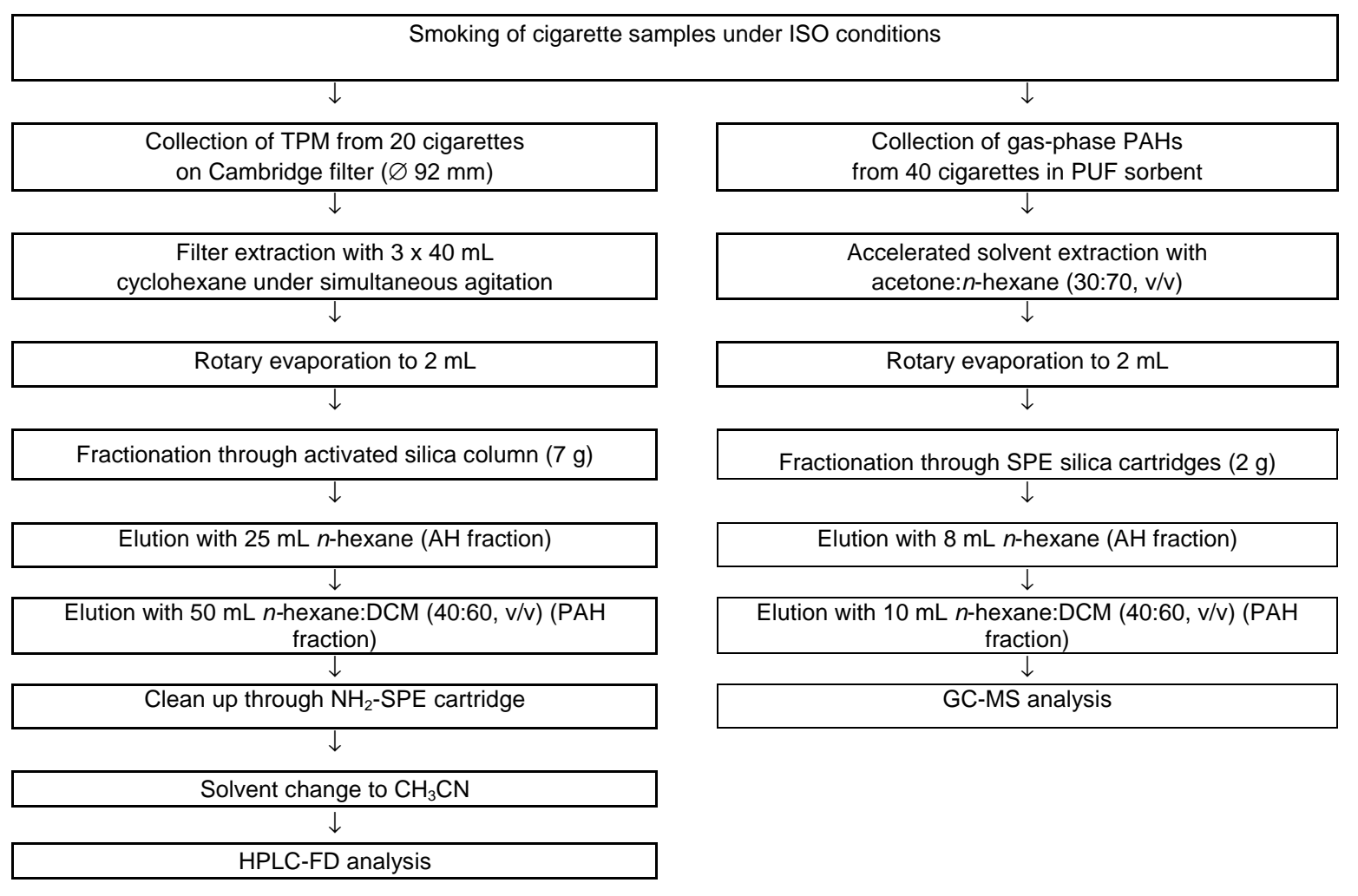

Figure 1. Diagram of the experimental procedure employed for the determination of PAHs in the particulate and the gas phase of cigarette mainstream smoke (abbreviations are explained in text)

finally to $\sim 1 \mathrm{~mL}$ under a gentle stream of nitrogen. Condensates were fractionated through silica SPE cartridges (2 g). After elution of the AH fraction with $8 \mathrm{~mL}$ of $n$-hexane, the PAH fraction was recovered by $8 \mathrm{~mL}$ hexane:DCM (40:60, $\mathrm{v} / \mathrm{v})$ mixture and concentrated to $200 \mu \mathrm{L}$. PAHs were analyzed by GC-MS in the SIM mode. The amount of $2-\mu \mathrm{L}$ sample volume was injected into a Hewlett Packard 5890 series II GC fitted with a heated $\left(280^{\circ} \mathrm{C}\right)$ splitless injection port. The injector was directly connected to HP-5MS capillary column $(30 \mathrm{~m}$ length, $0.25 \mathrm{~mm}$ i.d. and $0.25 \mu \mathrm{m}$ film thickness). The temperature program was as follows: $60{ }^{\circ} \mathrm{C}$ (1 min), $60-120{ }^{\circ} \mathrm{C}\left(10{ }^{\circ} \mathrm{C} / \mathrm{min}\right), 120-240{ }^{\circ} \mathrm{C}\left(5{ }^{\circ} \mathrm{C} / \mathrm{min}\right)$, $240-300{ }^{\circ} \mathrm{C}\left(3{ }^{\circ} \mathrm{C} / \mathrm{min}\right), 300{ }^{\circ} \mathrm{C}$ (30 min). Helium (flow rate $1 \mathrm{~mL} / \mathrm{min}$ ) was used as the carrier gas with both oxygen and moisture scrubbers connected in-line. The electron impact ionization conditions were the following: ion energy $70 \mathrm{eV}$, ion source temperature $180{ }^{\circ} \mathrm{C}$, electron multiplier voltage 2 $\mathrm{KV}$. GC-MS data were acquired and processed using the HP enhanced Chemstation software (version A.03.00). Identification of target analytes was accomplished by using authentic standards in combination with retention times and qualifier ions. The linear regression method was employed for quantification using five-point calibration curves established between the authentic standard/internal standard concentration ratios and corresponding peak area ratios. The diagram of the experimental procedures employed for the determination of PAHs in TPM and the gas phase of cigarette MSS is shown in Figure 1.

\section{Data validation}

The comparability of the HPLC-FD and the GC-MS procedures used for PAH analysis in TPM and the vapourphase MSS respectively was checked by parallel application on the particulate and gas phase of the MSS of the Cooperation Centre for Scientific Research Relative to Tobacco (CORESTA) CM3 reference brand. In both MSS phases, the two-tailed $F$-test and the paired $t$-test indicated that the two procedures are of equal precision and accuracy at the $95 \%$ confidence level.

In addition, blank filter pad and PUF samples were routinely analyzed to evaluate analytical bias and precision. Blank levels of individual PAHs were not detectable in both collection substrates. The estimated precision of compound quantification by HPLC-FD and GC-MS was better than $\pm 10 \%$. The recoveries of PAHs from TPM and PUFs were examined by analyzing samples spiked with low and high concentrations of standard compounds. Percent recoveries of PAHs from the TPM were in the range $72 \pm 4 \%$ for Chry and $114 \pm 3.6 \%$ for $\mathrm{B}[b] \mathrm{Fl}$, and only $\mathrm{Np}$ yielded lower and more variable recovery $(63 \pm 11 \%)$. Percent recoveries of PAHs from PUFs ranged between $65 \pm 9 \%$ for $\mathrm{dB}[\alpha, h] \mathrm{An}$ and $108 \pm 6 \%$ for Py. The precision of PAHs analysis in TPM was between $3-22 \%$ and 5-20\% in TPM and PUFs, respectively. The limit of detection (LOD) was in the range $0.04-0.75 \mathrm{ng} /$ cigarette for TPM and in the range $0.04-1.46$ for PUFs. 
Table 2. Classification of cigarette brands

\begin{tabular}{|c|c|c|c|c|c|}
\hline Cigarette class & Cigarette code & Filter $(\mathrm{Y} / \mathrm{N})^{\mathrm{a}}$ & Diameter $(\mathrm{mm})$ & Length (mm) & 'Tar' quoted on packet (mg/cig) ${ }^{b}$ \\
\hline Non filter & NF & $\mathrm{N}$ & & 68 & $13(1), 14(1), 15(1)$ \\
\hline High 'tar' yield & $\mathrm{H}$ & Y & 7.9 & 84 & $12(4), 13(3), 14(2)$ \\
\hline High 'tar' yield/100 mm & $\mathrm{H}-100$ & $\mathrm{Y}$ & 7.9 & 100 & $11(1), 12(3), 13(1), 14(1)$ \\
\hline Medium 'tar' yield & M & Y & 7.9 & 84 & $10(3)$ \\
\hline Light 'tar' yield & L & Y & 7.9 & 84 & $7(5), 8(4)$ \\
\hline Light 'tar' yield/100 mm & L-100 & Y & 7.9 & 100 & $8(2), 9(2), 10(1)$ \\
\hline Super light 'tar' yield & SL & Y & 7.9 & 84 & $5(1), 4(3)$ \\
\hline Super light 'tar' yield/100 mm & SL-100 & $\mathrm{Y}$ & 7.9 & 100 & $5(1)$ \\
\hline Super light 'tar' yield/Slim & SL-SLIM & Y & 6.3 & 84 & $6(2), 5(1)$ \\
\hline Ultra light 'tar' yield & UL & Y & 7.9 & 84 & $2(1), 1(4)$ \\
\hline Ultra light 'tar' yield/100 mm & UL-100 & $\mathrm{Y}$ & 7.9 & 100 & $3(1)$ \\
\hline Ultra light 'tar' yield/Slim & UL-SLIM & Y & 6.3 & 84 & $3(1)$ \\
\hline $1 \mathrm{mg}$ 'tar', $0.1 \mathrm{mg}$ nicotine & $\mathrm{O}$ & Y & 7.9 & 84 & $1(6)$ \\
\hline $\begin{array}{l}1 \mathrm{mg} \text { 'tar', } \\
0.1 \mathrm{mg} \text { nicotine } / 100 \mathrm{~mm}\end{array}$ & $0-100$ & Y & 7.9 & 84 & $1(1)$ \\
\hline $\begin{array}{l}1 \mathrm{mg} \text { 'tar', } \\
0.1 \mathrm{mg} \text { nicotine/Slim }\end{array}$ & O-SLIM & $\mathrm{Y}$ & 6.3 & 84 & $1(2)$ \\
\hline Reference cigarette & CORESTA CM3 & Y & 7.9 & 84 & $13(1)$ \\
\hline
\end{tabular}

${ }^{\text {a }} \mathrm{Y}=$ yes, $\mathrm{N}=$ no

${ }^{\mathrm{b}}$ The parentheses indicate the number of brands examined.

The CORESTA CM3 reference brand was also used for validation of TPM, 'tar', nicotine, $\mathrm{CO}$, moisture and puff number measurements. Results obtained were within $\pm 0.6 \%$ of certified values for 'tar' and $\mathrm{CO}$, within $\pm 2.4 \%$ for TPM and nicotine, and within $\pm 8.5 \%$ for moisture.

\section{RESULTS AND DISCUSSION}

\section{Classification of cigarettes}

In order to draw conclusions, the 59 examined brands of cigarettes were classified into 15 groups with respect to the existence of filter or not, the 'tar' indicated on the packet, and the cigarette dimensions (length and diameter). The classification of cigarettes is shown in Table 2.

\section{Concentration levels in particulate- and gas-phase MSS}

The yielded 'tar', nicotine and CO in the MSS of the studied cigarette brands were largely variable ranging between $0.8-14.76,1.31-0.08$, and $0.75-14.76 \mathrm{mg} / \mathrm{cigarette}$, respectively. Mean values for each cigarette class are presented in Tables 3 and 4. Non-filtered cigarettes (NF) delivered less $\mathrm{CO}$ than filter tipped cigarettes with comparable 'tar' yields, such as $\mathrm{H}-100$ and $\mathrm{H}$. The CO-to- 'tar' ratio ranged between $0.70-1.68$ (mean value 1.04) in individual brands being in consistency to literature data (18).

Mean \pm SD values of particulate-phase PAH concentrations in different classes of cigarettes are reported in Table 3. All 16 targeted PAHs were detectable in the particulate phase of all cigarette brands, and only $\mathrm{dB}[a, h]$ An yield was below the limit of quantification in some low 'tar' cigarettes. The concentrations of all PAHs were highest in non-filtered and high-'tar' cigarettes, while the lowest values were found in the one-'tar' yield slim class (OSLIM). In general, the PAH concentrations in the TPM of the commercial brands examined in the present study are comparable to results reported in literature $(16-19,31,32)$. Despite their different PAH content, the TPMs of the various cigarette classes exhibited quite similar PAH profiles (Figure 2), in which the lower molecular weight species (particularly $\mathrm{Np}$ and $\mathrm{F}$ ) exhibited relative abundances (14-30\%) proportionally greater than the less volatile, yet more carcinogenic $\mathrm{B}[b] \mathrm{Fl}(0.6-1.7 \%), \mathrm{B}[k] \mathrm{Fl}(0.2-0.6 \%)$, $\mathrm{B}[a] \mathrm{Py}(0.7-1.3 \%)$, IPy $(0.4-1.0 \%)$ or $\mathrm{dB}[a, h] \mathrm{An}$ $(0.2-0.6 \%)$. In all cigarette brands, concentrations followed the order: 2-3 ring PAHs > 4-ring PAHs > 5-6-ring PAHs.

The ratio of individual PAH concentrations in TPM to 'tar' yield (PAH/'tar'), often examined in relevant studies, are shown in Figure 3. Reported values for this ratio range between approximately $0.1-35 \mathrm{ng} / \mathrm{mg}$ with lower values for high molecular weight PAHs and higher values for the lighter species $(32,33)$. In the present study, the mean $\mathrm{PAH} /$ 'tar' ratio values ranged between 0.22 for $\mathrm{dB}[a, h] \mathrm{An}$ to 29.6 for F. In general, the PAH/'tar' ratio for a certain compound remained quite stable among different cigarette classes, however, some increased variability in the UL and $\mathrm{O}$ classes was evident. This variability might be attributed to one or both of the following reasons: a) the extremely low concentrations of PAHs, close to the limit of quantification, in the MSS of these brands, b) the tobacco material used in cigarettes with extremely low 'tar' and nicotine content, which may contain variable proportions of stems, woody plant parts, reconstructed tobacco, etc. Indeed, a larger chemical complexity of the MSS of the UL and O cigarette classes as compared to other categories was evident in the corresponding GC-MS and HPLC-FD chromatograms (34). EvANS et al. (32) has found lower $\mathrm{PAH} /$ 'tar' ratios for $\mathrm{B}[b] \mathrm{Fl}, \mathrm{B}[k] \mathrm{Fl}$ and $\mathrm{B}[a] \mathrm{Py}$ in SLIM cigarettes than in cigarettes with respective 'tar', however this was not observed here.

The mean PAH concentrations determined in the gas phase of MSS are reported in Table 4. In all cigarette brands, only eight $\mathrm{PAH}$ species were quantifiable at concentrations 


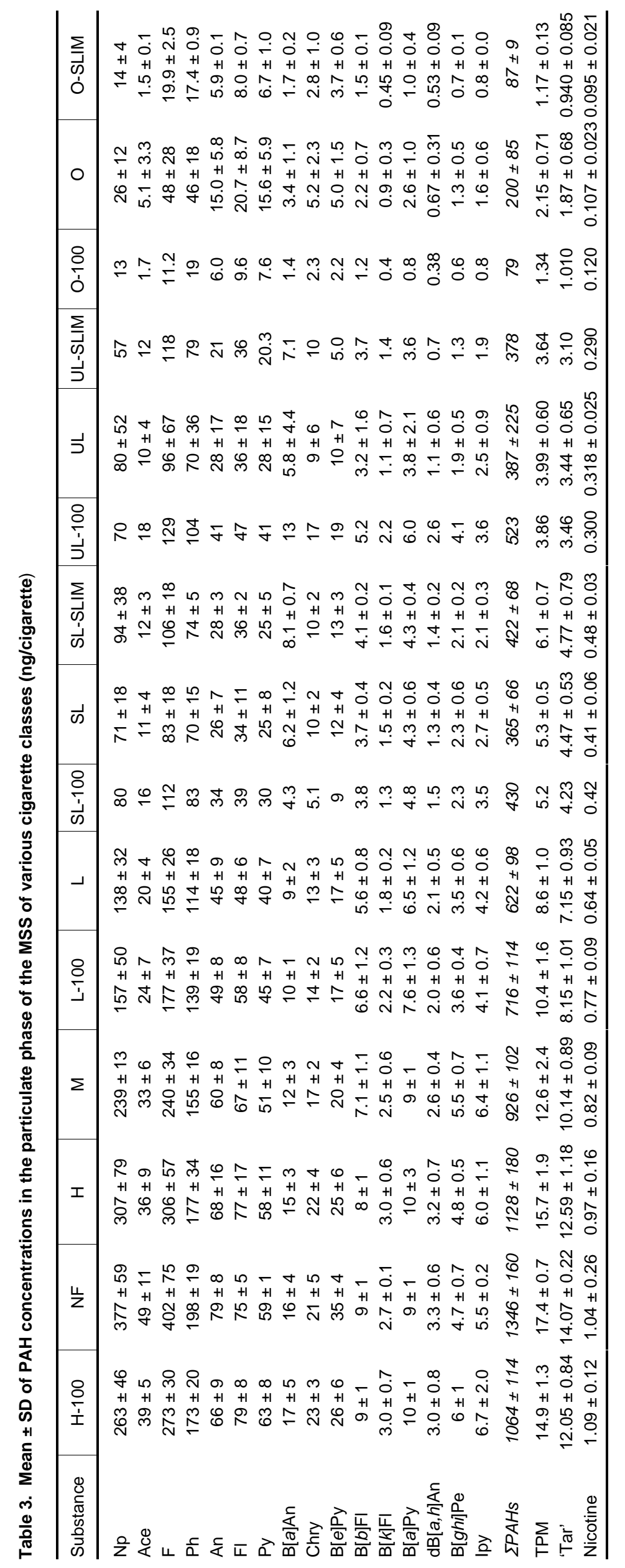




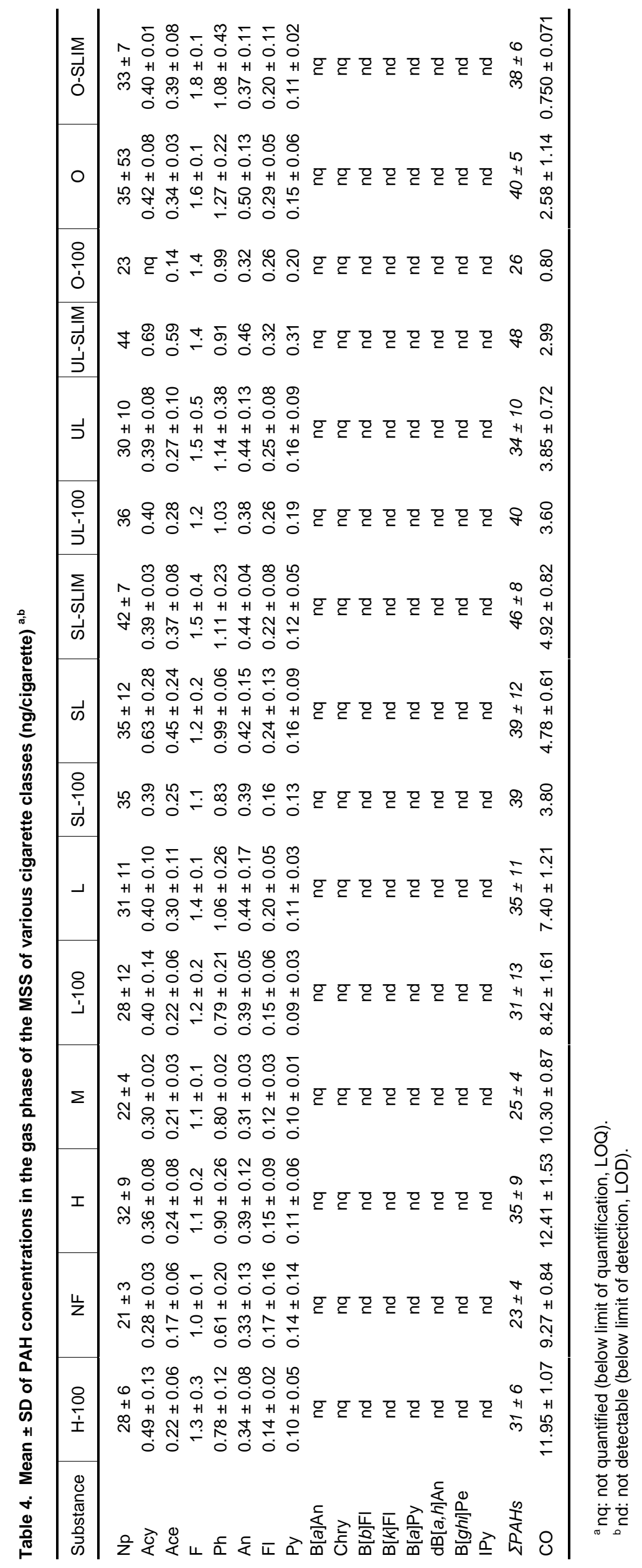



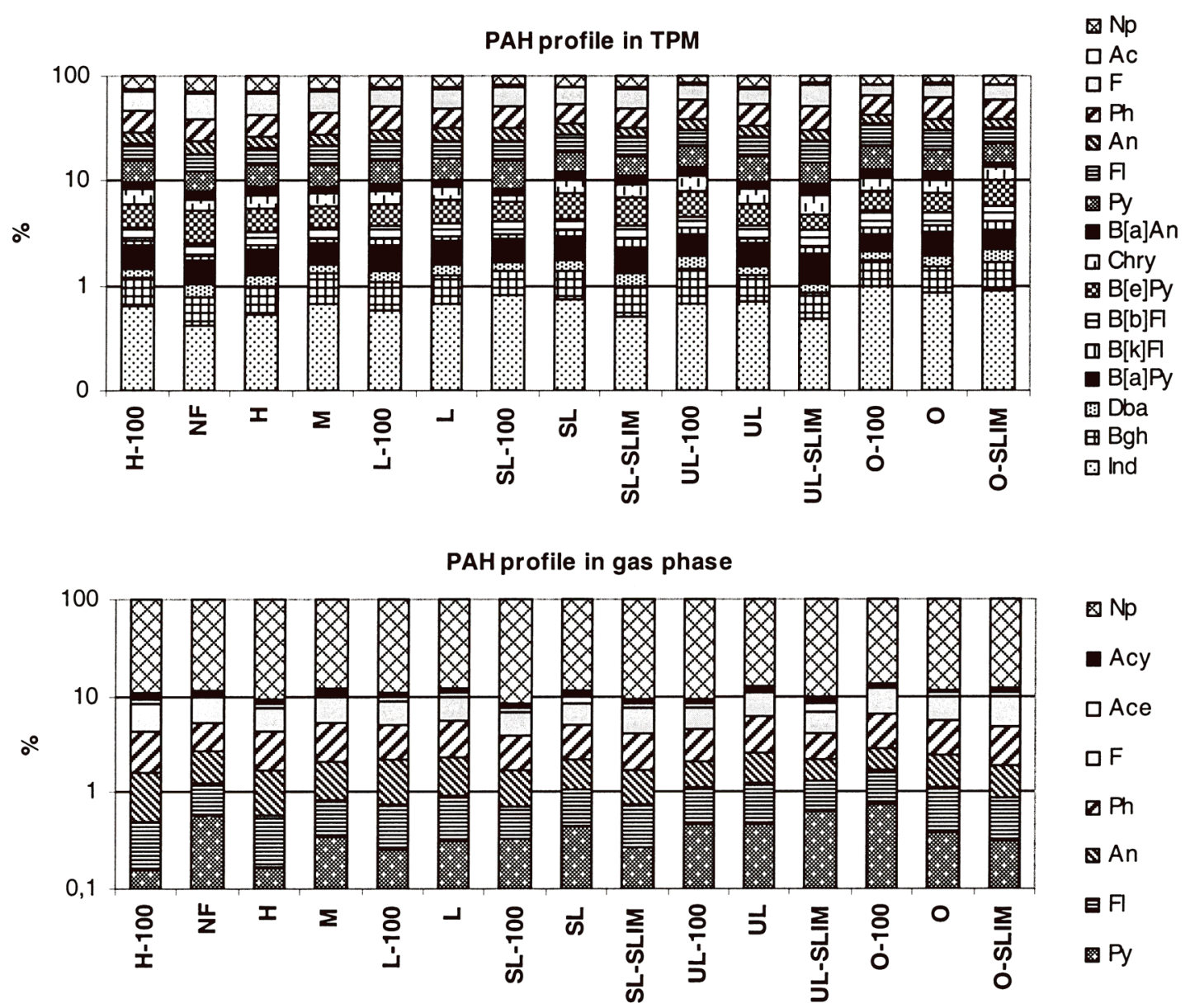

Figure 2. PAH profiles in the particulate and the gas phase of MSS from various cigarette classes (code names as quoted in Table 2)

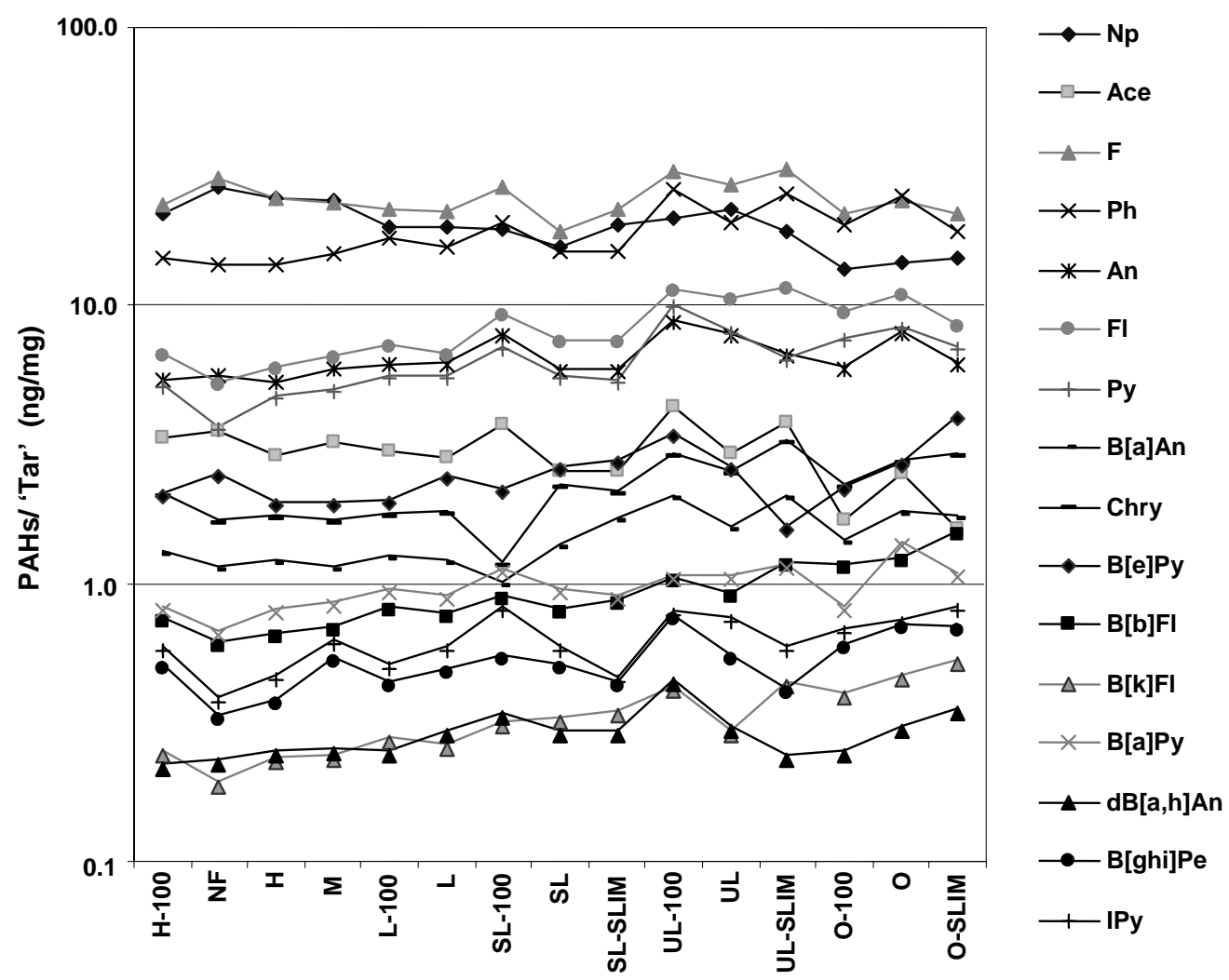

Figure 3. PAH/ 'tar' ratios in TPM for various cigarette classes (code names as quoted in Table 2) 


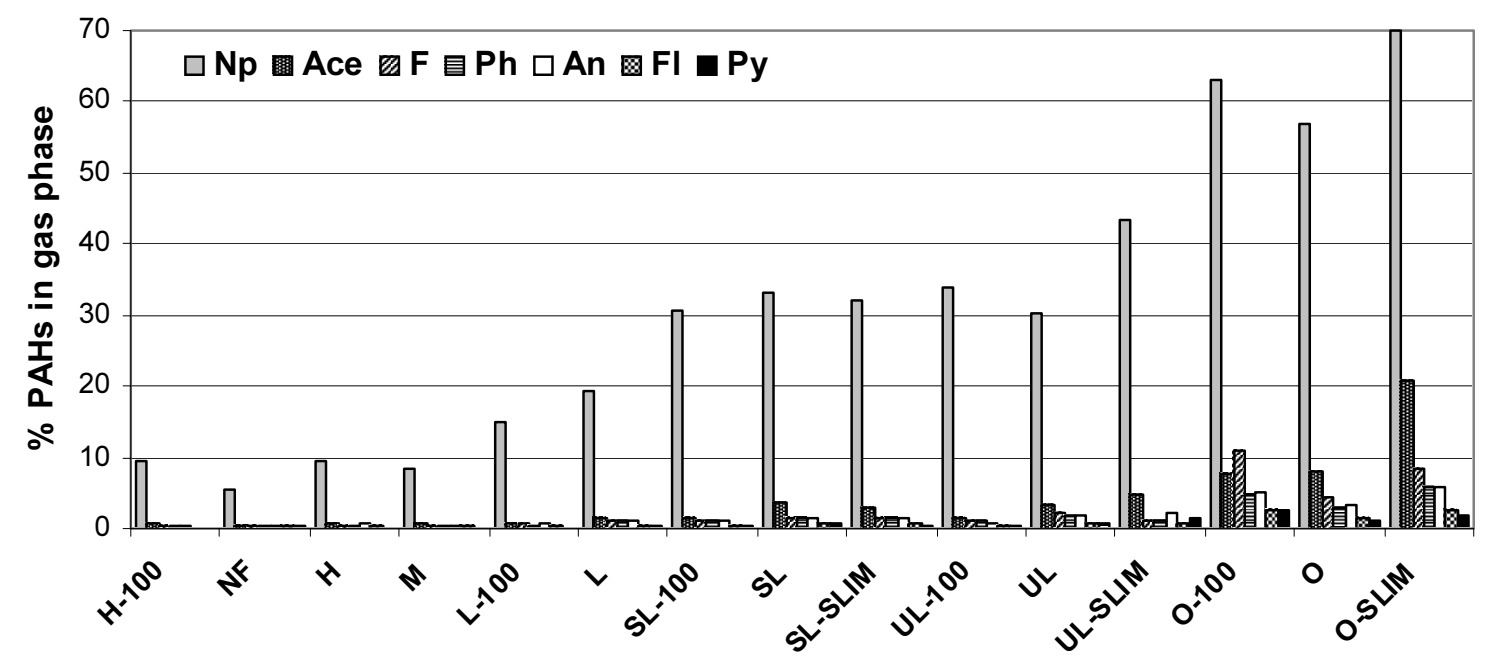

Figure 4. Percent PAHs in gas phase of various cigarette classes (code names as quoted in Table 2)

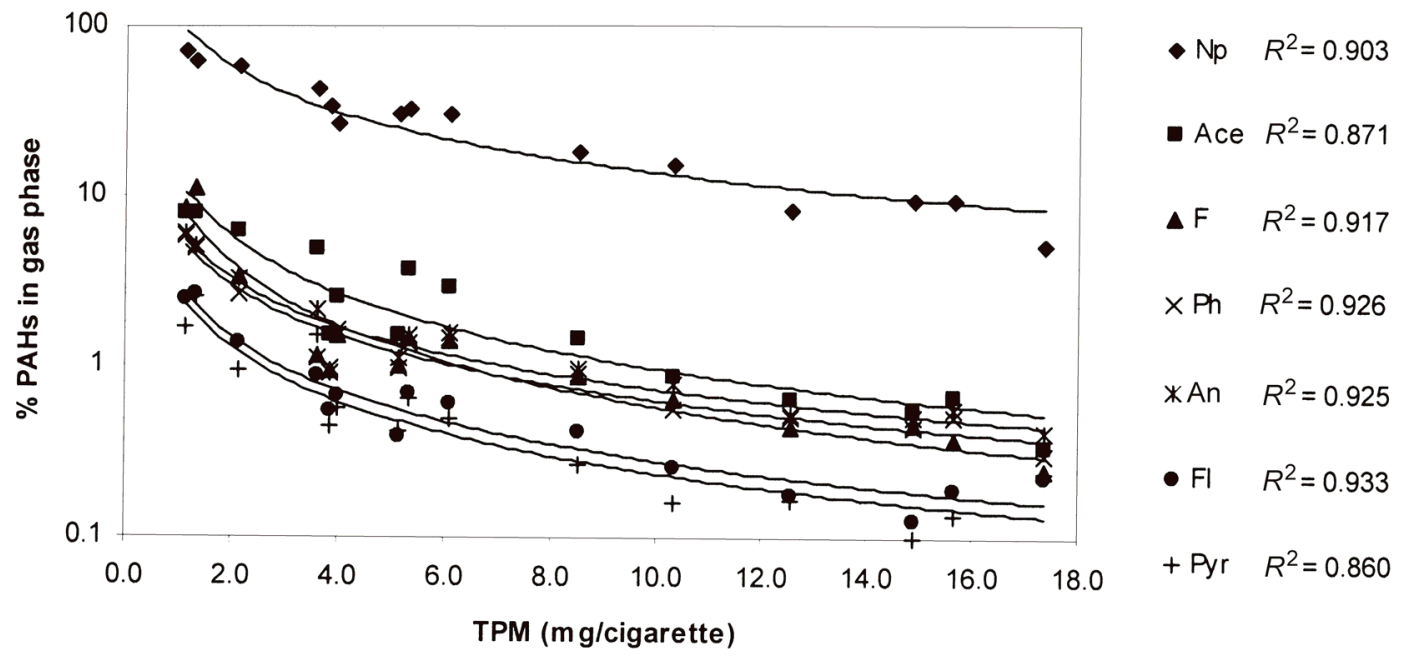

Figure 5. PAH distribution in gas phase as a function of TPM concentration

following the order: $\mathrm{Np}>\mathrm{F}>\mathrm{Ph}>\mathrm{An}>$ Acy $>$ Ace $>\mathrm{Fl}$ $>$ Py. B $[a]$ An and Chry, although detectable in certain cigarette brands, could not be quantified. In general, PAH concentrations ranged between $0.18-50.5 \mathrm{ng} /$ cigarette for Py and Np, respectively. Non filter tipped cigarettes presented the lowest values for gas-phase Np, Acy, Ace, F and $\mathrm{Ph}$ among all other classes probably due to the higher TPM content in their MSS as shown in Table 3 and/or to lower MSS temperature as reported in early studies (35). However, the PAH profiles in the gas-phase MSS were quite similar among the various cigarette classes (Figure 2).

The concentrations of all PAHs detected in the present study in the gas phase of cigarette MSS are in accordance with the values reported by GRIMMER et al. for these species (19). However, the very low levels reported by these investigators for some of the heavier PAHs (e.g. $0.08 \mathrm{ng} / \mathrm{cig}$ for $\mathrm{B}[a] \mathrm{Py})$ could not be determined here.

\section{Phase distribution of PAHs in MSS}

The percentage of the total PAH concentration distributed in the gas phase of MSS is shown in Figure 4. As seen, Np presented the highest gas-phase fraction, which however varied largely among the different cigarette classes (from around $10 \%$ in $\mathrm{H}-100$, NF, $\mathrm{H}$ and $\mathrm{M}$ to $70 \%$ in O-SLIM). The data of Figure 4 suggest that, in more concentrated smoke, as those produced by cigarettes with higher 'tar' yield, the distribution of PAHs in gas phase decreases. This could be attributed to the higher TPM concentrations in the higher 'tar' yield cigarette smoke (a strong linear correlation of TPM with 'tar' yield with $r=0.994, p=0.01$ was revealed), which favours the adsorption of PAHs on smoke particles. In Figure 5, the gas-phase PAH fraction has been plotted as a function of the TPM content of MSS. A good hyperbolic relationship of the type $y=a x^{-b}$ was found for all PAHs with $R^{2}$ values in the range $0.860(\mathrm{Py})-0.926(\mathrm{Ph})$. 
Table 5. Pearson correlation coefficients for particulate- and vapour-phase PAH concentrations with other MSS components ${ }^{a, b}$

\begin{tabular}{|c|c|c|c|c|c|c|c|c|}
\hline \multirow[b]{2}{*}{ Substance } & \multicolumn{4}{|c|}{ Particulate-phase PAHs } & \multicolumn{4}{|c|}{ Vapour-phase PAHs } \\
\hline & TPM & Nicotine & ‘Tar' & $\mathrm{CO}$ & TPM & Nicotine & 'Tar' & $\mathrm{CO}$ \\
\hline $\mathrm{Np}$ & 0.924 & 0.852 & 0.931 & 0.861 & -0.269 & -0.280 & -0.280 & -0.270 \\
\hline Acy $^{\mathrm{C}}$ & nd & nd & nd & nd & -0.149 & -0.121 & -0.157 & -0.102 \\
\hline Ace & 0.927 & 0.879 & 0.932 & 0.861 & -0.423 & -0.398 & -0.418 & -0.387 \\
\hline $\mathrm{F}$ & 0.941 & 0.877 & 0.945 & 0.858 & -0.580 & -0.558 & -0.591 & -0.547 \\
\hline $\mathrm{Ph}$ & 0.941 & 0.895 & 0.944 & 0.895 & -0.507 & -0.544 & -0.508 & -0.460 \\
\hline An & 0.932 & 0.897 & 0.929 & 0.871 & -0.279 & -0.330 & -0.278 & -0.271 \\
\hline $\mathrm{FI}$ & 0.924 & 0.913 & 0.923 & 0.905 & -0.515 & -0.610 & -0.523 & -0.554 \\
\hline Py & 0.918 & 0.898 & 0.916 & 0.886 & -0.456 & -0.545 & -0.463 & -0.534 \\
\hline $\mathrm{B}[\mathrm{a}] \mathrm{An}{ }^{\mathrm{d}}$ & 0.858 & 0.849 & 0.870 & 0.825 & $\mathrm{nq}$ & $\mathrm{nq}$ & $\mathrm{nq}$ & nq \\
\hline Chry $^{d}$ & 0.883 & 0.862 & 0.889 & 0.872 & $\mathrm{nq}$ & nq & $\mathrm{nq}$ & $\mathrm{nq}$ \\
\hline $\mathrm{B}[e] \mathrm{Py}^{\mathrm{d}}$ & 0.874 & 0.808 & 0.884 & 0.798 & $\mathrm{nq}$ & $\mathrm{nq}$ & $\mathrm{nq}$ & $\mathrm{nq}$ \\
\hline $\mathrm{B}[b] \mathrm{FI}^{\mathrm{d}}$ & 0.940 & 0.921 & 0.945 & 0.907 & $\mathrm{nq}$ & $\mathrm{nq}$ & $\mathrm{nq}$ & $\mathrm{nq}$ \\
\hline $\mathrm{B}[k] \mathrm{FI}^{\mathrm{d}}$ & 0.885 & 0.879 & 0.893 & 0.869 & $\mathrm{nq}$ & $\mathrm{nq}$ & $\mathrm{nq}$ & $\mathrm{nq}$ \\
\hline $\mathrm{B}[\mathrm{a}] \mathrm{Py}^{\mathrm{d}}$ & 0.927 & 0.904 & 0.926 & 0.917 & $\mathrm{nq}$ & $\mathrm{nq}$ & $\mathrm{nq}$ & nq \\
\hline $\mathrm{dB}[a, h] \mathrm{An}^{\mathrm{d}}$ & 0.873 & 0.823 & 0.880 & 0.848 & nq & nq & nq & nq \\
\hline $\mathrm{B}[g h i] \mathrm{Pe}^{\mathrm{d}}$ & 0.891 & 0.868 & 0.901 & 0.899 & $\mathrm{nq}$ & $\mathrm{nq}$ & $\mathrm{nq}$ & $\mathrm{nq}$ \\
\hline $\mathrm{IPy}^{\mathrm{d}}$ & 0.890 & 0.883 & 0.891 & 0.890 & nq & nq & $\mathrm{nq}$ & $\mathrm{nq}$ \\
\hline$\Sigma$ PAHs & 0.963 & 0.907 & 0.967 & 0.901 & -0.308 & -0.320 & -0.319 & -0.306 \\
\hline
\end{tabular}

${ }^{a}$ Concentrations below the detection limits were considered as equal to the half of the detection limit.

${ }^{\mathrm{b}}$ Correlation coefficients in bold are significant at the 0.01 level. Coefficients in italics are significant at the 0.05 level.

${ }^{\mathrm{c}} \mathrm{nd}=\mathrm{Acy}$ was not determined in the particulate-phase of MSS.

${ }^{\mathrm{d}} \mathrm{nq}=\mathrm{PAHs}$ not quantified in gas-phase.

However, other factors as well could influence the distribution of PAHs in the gas phase of MSS, and cigarette ventilation appears to be one of the most likely, as discussed below.

The Pearson correlation coefficients between the PAH concentrations in the two phases of MSS and other chemical parameters are given in Table 5. A reasonably strong positive linear correlation between particulate phase PAHs and TPM, 'tar', nicotine and CO was evident for all 16 PAH compounds. CHEPIGA et al. (4) also found strong positive correlation between the particulate-phase PAH levels in MSS and 'tar' delivery. The relationship between particulate-phase PAHs and 'tar' is shown in Figure 6. All PAHs were linearly related to 'tar' with $R^{2}$ values ranging from 0.779 for $\mathrm{dB}[a, h]$ An to 0.892 for F. PAHs with high abundances in MSS exhibited in general better 'tar' correlation. It is noteworthy to say that the relationship between particulate-phase PAH levels and 'tar' delivery appears to be unaffected by the large differences in design characteristics among the various cigarette brands, thus suggesting that particulate-phase MSS constituents levels are well predicted by the 'tar' yield. The relationship between $\mathrm{B}[a] \mathrm{P}$ and 'tar' yield in MSS has been investigated by several researchers, however, with contradictory conclusions. KAISERMAN and RICKERT (36) claimed that, despite their linear relationship, 'tar' was not a good predictor of $\mathrm{B}[a] \mathrm{Py}$ because of the wide scatter around the regression line $\left(R^{2}=\right.$ 0.89 for 35 cigarette brands). In a Laboratory of the Government Chemist of UK (LGC) study (18) involving 60 cigarette brands, it was also reported considerable scatter around the regression line $\left(R^{2}=0.65\right)$. On the contrary, CHEPIGA et al. (4) found $R^{2}=0.96$ for 29 market brands.

Vapour-phase PAH concentrations exhibited weak negative linear correlations with TPM, which were statistically sig- nificant ( $p=0.01$ ) only for Ace, F, Ph, Fl and Py (Table 5). Similarly poor negative correlations were also observed with nicotine, 'tar' and CO.

\section{MSS PAHs in relation to design characteristics of cigarettes}

The correlation coefficients between the sum concentrations of PAHs determined in the particulate and the gas phase of MSS ( $\mathrm{P} A H \mathrm{H})$ and the technological characteristics of cigarettes are given in Table 6 . Strong negative correlation was observed for particulate-phase $\Sigma$ PAH concentrations with tip ventilation that could be attributed to the dilution of cigarette smoke. A similar effect of cigarette ventilation has also been reported for nicotine in MSS (37). Ventilated filters alter pyrolytic conditions, increase the residence time of smoke gases in the tobacco column, alter the flow pattern, and decrease the flow rate of smoke in the cigarette filter. Consequently, the amounts of most smoke components, including the fraction of semivolatiles, are reduced and the chemical composition of smoke is altered. The slower flow rate through the cigarette column enables significant amounts of low molecular weight gases, such as $\mathrm{CO}$, to diffuse out of the cigarette, while the lower flow rate through the filter facilitates increased filtration efficiencies (38).

Surprisingly, a positive correlation, although not as strong as those found for tip ventilation, was observed for paper ventilation. Both the tip and paper ventilation contribute to the total ventilation of cigarette, but the contribution of the latter is expected to become less significant with decreasing the cigarette length during smoking (39). The fact that the correlation coefficient of particulate-phase $\Sigma$ PAH levels with total ventilation was identical to those with tip ventila- 

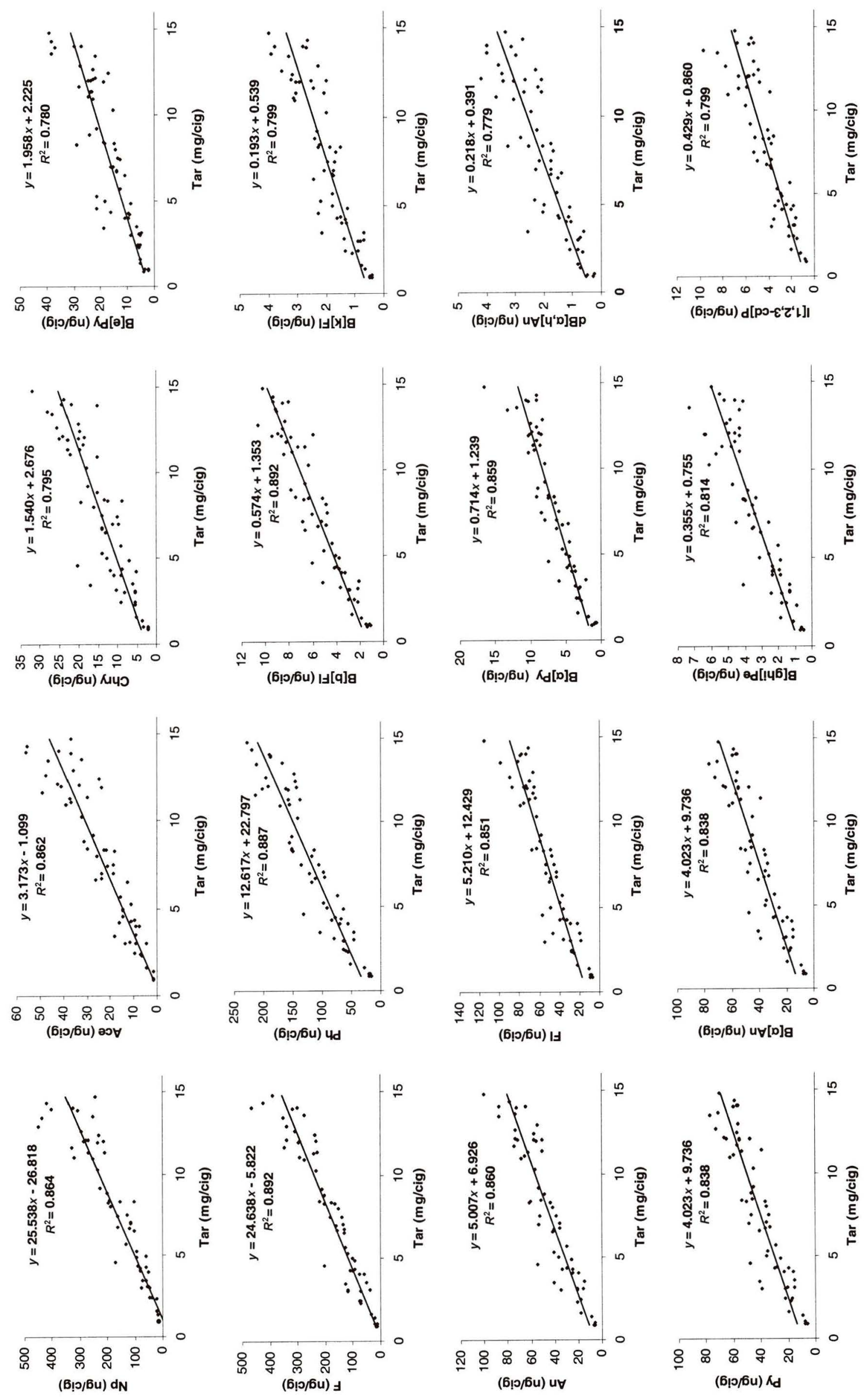

Figure 6. PAH concentrations in TPM as a function of 'tar' yields 
Table 6. Pearson correlation coefficients for particulate- and vapour- phase $\mathrm{IPAH}$ concentrations with cigarette design characteristics $^{\text {a }}$

\begin{tabular}{lcc}
\hline Characteristics & $\begin{array}{c}\text { Particulate- } \\
\text { phase PAHs }\end{array}$ & $\begin{array}{c}\text { Gas-phase } \\
\text { PAHs }\end{array}$ \\
\hline Cigarette weight (g) & $\mathbf{0 . 3 4 2}$ & -0.244 \\
Puff number & 0.077 & -0.023 \\
Cigarette length (mm) & -0.249 & 0.175 \\
Tip length (mm) & -0.304 & -0.018 \\
Cigarette diameter (mm) & 0.207 & -0.231 \\
Cigarette ventilation (\%) & $-\mathbf{0 . 9 0 2}$ & 0.267 \\
Tip ventilation (\%) & $-\mathbf{0 . 9 0 5}$ & 0.220 \\
Paper ventilation (\%) & $\mathbf{0 . 7 3 9}$ & -0.148 \\
Pressure drop open (mm water) & 0.136 & 0.042 \\
Pressure drop closed (mm water) & $-\mathbf{0 . 7 6 4}$ & 0.310 \\
\hline
\end{tabular}

${ }^{a}$ Correlation coefficients in bold are significant at the 0.01 level. Coefficients in italics are significant at the 0.05 level.

tion (Table 6) supports this hypothesis. In Figure 7, the \%PAHs in the gas phase of MSS has been plotted as a function of the total cigarette ventilation. It is evident that an increase in ventilation is associated with an increase in the gas-phase PAH fraction. Good exponential relationships of the type $y=a e^{b x}$ were exhibited by all seven PAHs with $R^{2}$ values in the range $0.774(\mathrm{~F})-0.948(\mathrm{~Np})$.

A significant negative correlation was found between particulate-phase $\mathrm{PPAHs}$ and the pressure drop closed (PDC). PDC is the sum of pressure drops due to filter and tobacco column. High filter pressure drop means increased filter efficiency resulting from more dense acetate cellulose fibres, and the use of additives. The pressure drop of tobacco column is related to packing density, and its increase is associated initially with an increase and then with a reduction of TPM. From the data of Table 6 it could be suggested that, as the PDC increases, volatilization of particulate-phase PAHs is occurring in a similar manner as during sampling of ambient air PAHs under high sampling rates (40). This hypothesis is supported by the low, yet significant at the 0.05 level, correlation of PCD with the gas-phase $\Sigma$ PAHs $r=0.310$, Table 6).
Finally, particulate-phase $\Sigma$ PAHs concentrations were negatively correlated with tip length, probably due to the better filtration efficiency resulted from the longer butt, and positively with cigarette weight, as a result of the higher tobacco content.

\section{CONCLUSIONS}

Sixteen PAHs were determined in the particulate and the gas phase of the MSS of several cigarette brands with variable 'tar' yields and technological characteristics. The particulate-phase PAH concentrations (ng/cig) exhibited significant positive linear relationships with TPM, 'tar', nicotine and $\mathrm{CO}$, in contrast to the gas-phase PAH levels that showed weak negative correlations with all chemical constituents of MSS. Ventilation among all cigarette design characteristics examined was found to significantly affect the distribution of PAHs between the particulate and the gaseous phase. High ventilation rates favor the reduction of TPM content in MSS and the desorption of particulate-phase PAHs. A significant negative correlation was also observed between the particulate-phase PAHs and the pressure drop of closed cigarette (PDC) suggesting that high PDC values, such as in the case of light cigarettes, favor the distribution of PAHs in the gas phase. Finally, particulate-phase $\Sigma$ PAH concentrations were negatively correlated with tip length, probably due to the better filtration efficiency resulting from the longer butt, and positively with cigarette weight, as a result of the higher tobacco content.

\section{ACKNOWLEDGEMENTS}

The authors wish to thank Dr. A. Koura from the Environmental Pollution Control Laboratory, University of Thessaloniki, as well as Dr. J. Lintelmann from the Institute of Ecological Chemistry, GSF, Munich, for providing valuable technical assistance in PAH analyses and helpful discussion.

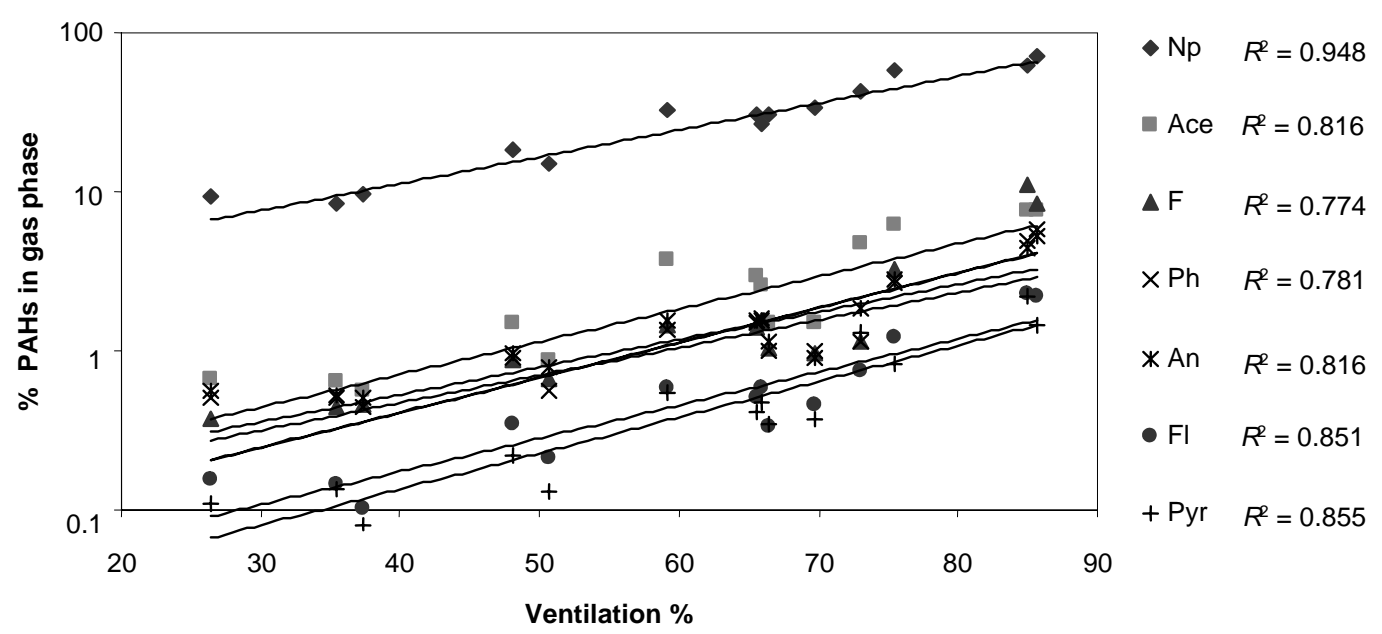

Figure 7. PAH distribution in gas phase as a function of cigarette ventilation 


\section{REFERENCES}

1. Baker, R.R.: Smoke chemistry; in: Tobacco: Production, chemistry and technology; edited by D.L. Davis and M.T. Nielsen, Blackwell Science, Oxford, 1999, pp. 398-439.

2. Hoffmann, D., I. Hoffmann, and K. El-Bayoumy: The less harmful cigarette: A controversial issue. A tribute to Ernst L. Wynder; Chem. Res. Toxicol. 14 (2001) 767-790.

3. Rustemeier, K., R. Stabbert, H.J. Haussmann, E. Roemer and E.L. Carmines: Evaluation of the potential effects of ingredients added to cigarettes. Part 2: Chemical composition of mainstream smoke; Food Chem. Toxicol. 40 (2002) 93-104.

4. Chepiga, T.A., M.J. Morton, P.A. Murphy, J.T. Avalos, B.R. Bombick, D.J. Doolittle, M.F. Borgerding, and J.E. Swauger: Comparison of the mainstream smoke chemistry and mutagenicity of a representative sample of the US cigarette market with two Kentucky reference cigarettes (K1R4F and K1R5F); Food Chem. Toxicol. 38 (2000) 949-962.

5. Snook, M.E., R.F. Severson, H.C. Higman, R.F. Arrendale, and O.T. Chortyk: Polynuclear aromatic hydrocarbons of tobacco smoke: Isolation and indentification; Beitr. Tabakforsch. Int. 8 (1976) 250-272.

6. Severson, R.F., M.E. Snook, and R.F. Arrendale: Gas chromatographic quantitation of polynuclear aromatic hydrocarbons in tobacco smoke: Analytic laboratory methods; Anal. Chem. 48 (1976) 1866-1872.

7. Adams, J.D., K.J. O Mara, and D. Hoffmann: Toxic and carcinogenic agents in undiluted mainstream smoke and sidestream smoke of different types of cigarettes; Carcinogenesis 8 (1987) 729-731.

8. Badger, G.M., J.K. Donelly, and T.M. Spotswood: The formation of aromatic hydrocarbons at high temperatures: XXIV. The pyrolysis of some tobacco constituents; Aust. J. Chem. 18 (1965) 1249-1266.

9. Lam, J., B.O. Pedersen, and T. Thomasen: Pyrolytic disintegration of selected tobacco constituents and pyrosynthetic formation of aromatic hydrocarbons from cleavage products formed by pyrolysis; Beitr. Tabakforsch. Int. 13 (1985) 1-5.

10. Rodgman, A: Studies of polycyclic aromatic hydrocarbons in cigarette mainstream smoke: Indentification, tobacco precursors, control of level: A review; Beitr. Tabakforsch. Int. 19 (2001) 361-379.

11 Smith, C.J, T.A. Perfetti, M.A. Rumple, A. Rodgman, and D.J. Doolittle: "IARC Group 2A Carcinogens" reported in cigarette mainstream smoke; Food Chem. Toxicol. 38 (2000) 371-383.

12. Smith, C.J, T.A. Perfetti, M.A. Rumple, A. Rodgman, and D.J. Doolittle: "IARC Group 2B Carcinogens" reported in cigarette mainstream smoke; Food Chem. Toxicol. 38 (2001) 825-848.

13. EPA/625/R-96/010b, 1999: Compendium of methods for the determination of toxic organic compounds in ambient air; Second Edition, Compendium Method TO-13A.

14. Dube, M.F. and C.R. Green. Methods of collection of smoke for analytical purposes; Rec. Adv. Tob. Sci 8 (1982) 3-41.
15. Nunziata, A., S. Maurizis, S. Rossi, and G. Lionetti: Selective extraction method of polycyclic aromatic compounds from tobacco smoke condensate and quantitative determination by HPLC - UV and fluorescence detection; Proceedings of CORESTA Congress, New Orleans, USA, 2002, S27.

16. Gmeiner, G., G. Stehlik, and H. Tausch: Determination of seventeen polycyclic aromatic hydrocarbons in tobacco smoke condensate; J. Chromatogr. 767A (1997) 163-169.

17. Forehand, J.B., G.L. Dooly, and S.C. Moldoveanu: Analysis of polycyclic aromatic hydrocarbons, phenols and aromatic amines in particulate phase cigarette smoke using simultaneous distillation and extraction as a sole sample clean-up step; J. Chromatogr. 898A (2000) 111-124.

18. LGC Report GC15/M09/02: 2002 Comparison of mainstream smoke yields of tar, nicotine, carbon monoxide and polycyclic aromatic hydrocarbons from cigarettes and small cigars; Commissioned by UK Department of Health Smoking Policy Unit. www.advisory bodies.doh.gov.uk/scoth/pdfs/cigarcigarettepah.pdf.

19. Grimmer, G., K.W. Naujack, and G. Dettbarn: Gas chromatographic determination of polycyclic aromatic hydrocarbons azarenes aromatic amines in the particulate and vapour phase of mainstream and sidestream smoke of cigarettes; Toxicol. Lett. 35 (1987) 117-124.

20. ISO 3402(E): Tobacco and tobacco products - Atmosphere for conditioning and testing; Fourth edition, International Organization for Standardization, Geneva, 1999.

21. ISO 3308(E): Routine analytical cigarette smoking machine - Definitions and standard conditions; International Organization for Standardization, Geneva, 2000.

22. ISO 4387(E): Cigarettes - Determination of total and nicotine free dry particulate matter using a routine analytical smoking machine; Third edition, International Organization for Standardization, Geneva, 2000.

23 ISO 8454(E): Cigarettes - Determination of carbon monoxide in vapour phase of cigarette smoke NDIR method; Second edition, International Organization for Standardization, Geneva, 1995.

24. ISO 10315(E): Cigarettes - Determination of nicotine in smoke condensates gas chromatographic method; Second edition, International Organization for Standardization, Geneva, 2000.

25. ISO 10362-1(E): Cigarettes - Determination of water in smoke condensates gas chromatographic method; Second edition, International Organization for Standardization, Geneva, 1999.

26. Wingen, M.L., C.J. Low, and J.B. Finlayson-Pitts: Chromatography, absorption, and fluorescence: A new instrumental analysis experiment on the measurement of polycyclic aromatic hydrocarbons in cigarette smoke; J. Chem. Educ. 75 (1998) 1599-1603.

27. HCTCP, Health Canada tobacco control program, 1999, Ottawa, Canada K1A 0K9, www.hc-sc.gc.ca.

28. Phillips, G.F.and R.E. Waller: Yields of tar and other smoke components from UK cigarettes; Food Chem. Toxicol. 29 (1991) 469-474.

29. Alexandrou, N., M. Smith, R. Park, K. Lumb, and K. Brice: The extraction of polycyclic aromatic hydrocar- 
bons from atmospheric particulate matter samples by accelerated solvent extraction (ASE); Int. J. Environ. An. Ch. 81 (2001) 257-280.

30. Maddalena, R.L., E.T. Mckone, and N.Y. Kado: Simple and rapid extraction of polycyclic aromatic hydrocarbons collected on polyurethane foam adsorbent; Atmos. Environ. 32 (1998) 2497-2503.

31. LGC Report FN40/M14/00, 2000: Cigarette yields using intense smoking protocols. Part 2 - Polycyclic aromatic hydrocarbon yields; Commissioned by UK Department of Health Smoking Policy Unit, www. advisorybodies.doh.gov.uk/scoth/technicaladvisory group/yieldintense1.pdf.

32. Evans, W.H., N.C. Thomas, and M.C. Boardman: Relationships of polycyclic aromatic hydrocarbon yields with particulate matter (water and nicotine free) yields in mainstream and sidestream cigerette smoke; Sci. Total Environ. 136 (1993) 101-109.

33. Christacopoulos, A.: Mass fragmentographic determination of polycyclic aromatic hydrocarbons (PAH) in cigarette smoke condensates; Proceedings of the CORESTA Congress, Harare, 1994, pp. 187-190.

34. Rogers, J., L. Winkler, and M. Borgerding: Chromatographic profiling as a tool in the comparison and the evaluation of complex mixtures; J. Chromatogr. Sci 33 (1997) 193-200.

35. Bigger, G.B., R. Spivey, and C.J. Moll: Measurements of cigarette mainstream smoke temperature; Brown Williamson Tobacco Corporation Research Department (1960). Report 620845588, http://legacy.library. ucsf.edu/tid/cdo70f00.

36. Kaiserman, M.J and W.S. Rickert: Carcinogens in tobacco smoke: Benzo[a]pyrene from Canadian cigarettes and cigarette tobacco; Am. J. Pub. Health 82 (1992) 1023-1026.

37. Mariner, D.C. and B.E. Frost: Determination of nicotine evapouration from mainstream smoke using denuder; Proceedings of CORESTA Congress, Brighton, UK, 1998, pp. 206-210.
38. Baker, R.R: The effect of ventilation on cigarette combustion mechanisms; Rec. Adv. Tob. Sci. 10 (1984) 88-150.

39. Rasmussen, G.T. and L.W. Renfro: Estimating the effects of alternative smoking regimes on the performance of filter cigarettes; Proceedings of CORESTA Congress, Brighton, England, 1989, ST15.

40. Samara, C.: Analysis of organic particulate matter; in: Airborne particulate matter. The handbook of environmental chemistry; edited by T. Kouimtzis and C. Samara, 4-D, Springer-Verlag, Berlin, Heidelberg, 1995, pp. 233-251.

41. DiGiovanni, J., T.J. Slaga, D.L. Berry, and M.R. Juchau: Inhibitory effects of environmental chemicals on polycyclic aromatic hydrocarbon carcinogenesis, in: Carcinogenesis. A comprehensive survey, Vol. 5, edited by T.J. Slaga, Raven Press, New York, NY, 1980, pp.145-168.

42. Slaga, T.J., L. Jecker, W.M. Bracken, and C.E. Weeks: The effects of weak or non-carcinogenic polycyclic aromatic hydrocarbons on 7,12-dimethylbenz $[a]$ anthracene and benzo $[a]$ pyrene, Cancer Lett. 7 (1979) 51-59.

\section{Corresponding author:}

Environmental Pollution Control Laboratory

Department of Chemistry

Aristotle University

54124 Thessaloniki

Greece

E-mail: csamara@chem.auth.gr 